\title{
Primeiro Relato da Podridão da Estipe da Pupunheira, Causada por Phytophthora palmivora, no Estado do Paraná
}

\author{
Álvaro F. dos Santos ${ }^{1 *}$, Edna Dora. M. N. Luz ${ }^{2 *}$, Priscila D. Finato ${ }^{1}$, Dauri J. Tessmann ${ }^{3}$ \& João B. Vida ${ }^{3}$ \\ ${ }^{1}$ Embrapa Florestas, Cx. Postal 319, CEP 83411-000, Colombo, PR, ${ }^{2}$ CEPLAC/CEPEC/SEFIT, Cx. Postal 07, \\ CEP 45600-970, Ilhéus, BA; ${ }^{3}$ Universidade Estadual de Maringá, Departamento de Agronomia, Av. Colombo 5790, \\ CEP 87020-900, Maringá, PR, e-mail: alvaro@cnpf.embrapa.br
}

(Aceito para publicação em 14/06/2004)

Autor para correspondência: Álvaro F. dos Santos

SANTOS, A.F. DOS, LUZ, E.D.M.N., FINATO, P.D., TESSMANN, D.J. \& VIDA, J.B. Primeiro relato da podridão da estipe da pupunheira, causada por Phytophthora palmivora, no estado do Paraná. Fitopatologia Brasileira 29:680-682. 2004.

\section{RESUMO}

Phytophthora palmivora foi isolado de plantas de pupunheira (Bactris gasipaes) com sintomas de podridão da estipe, no Paraná, em 2002. Testes de patogenicidade e o subseqüente reisolamento do fungo confirmaram a hipótese de que $P$. palmivora é o agente causal da podridão do estipe. Este é o primeiro relato de P. palmivora causando podridão do estipe na pupunheira no estado do Paraná.

Palavras-chave adicionais: pupunha, Bactris gasipaes.

\section{ABSTRACT}

First report of stem rot on peach palm caused by Phytophthora palmivora ain the State of Paraná

Phytophthora palmivora was isolated from infected peach palm (Bactris gasipaes) plants with stem rot symptoms in Paraná State, in
2002. Pathogenicity tests and subsequent reisolations of $P$. palmivora confirmed the hypothesis that this fungus was the causal agent of the disease. This is the first report of P. palmivora causing stem rot on peach palm (Bactris gasipaes) in the southern State of Paraná.
A pupunha (Bactris gasipaes Kunth) cultivada para a produção de palmito é uma alternativa de diversificação da atividade produtiva e fonte de renda para a pequena propriedade rural no Estado do Paraná. No ano de 2002, constatou-se a morte de plantas de pupunheira em plantios com idade entre seis e 12 meses, localizados em Paranaguá, litoral do Paraná. As plantas atacadas caracterizavam-se pelo amarelecimento da folha bandeira (Figura 1), seguido do amarelecimento e morte das demais folhas. Ao se realizar um corte transversal na base do estipe observava-se o escurecimento dos tecidos internos (Figura 2), com posterior, podridão generalizada. As plantas com sintomas de podridão do estipe encontravam-se distribuídas esparsamente na plantação. Este trabalho teve o objetivo de identificar e caracterizar o agente causal da podridão do estipe da pupunheira, e demonstrar também sua patogenicidade.

Foram coletadas amostras de tecidos do estipe de plantas doentes em diferentes estágios sintomatológicos, localizados na base e a $20 \mathrm{~cm}$ de altura. $\mathrm{O}$ isolamento consistiu na retirada de fragmentos destes tecidos da porção interna do estipe e deposição em placas de Petri contendo ágar-água $2 \%$ com ampicilina, cloranfenicol e benomyl (Santos, 2001). As placas foram incubadas a $25^{\circ} \mathrm{C}$, no escuro, por quatro a seis dias. Após este período, foi isolado em cultura pura um oomiceto com as características do gênero Phytophthora. As colônias foram transferidas para placas de Petri contendo

\footnotetext{
* Bolsistas do CNPq.
}

batata-dextrose-ágar (BDA). Procedeu-se, então, a caracterização morfo-fisiológica de dois isolados, BG-17 e BG-26, visando à identificação da espécie (Waterhouse, 1970; Newhook et al., 1978; Ribeiro, 1978; Stamps et al., 1990).

Para avaliação do crescimento micelial e caracterização das colônias, discos de $7 \mathrm{~mm}$ de diâmetro obtidos da margem de colônias do fungo produzidas em meio de BDA foram transferidos assepticamente para placas de Petri de $90 \mathrm{~mm}$ de diâmetro contendo meio cenoura-ágar (CA) (200 g de cenoura, $17 \mathrm{~g}$ de ágar e $1.000 \mathrm{ml}$ de água destilada) e suco V8-ágar (200 ml de suco V-8 Campbell, $3 \mathrm{~g}$ de carbonato de cálcio, $18 \mathrm{~g}$ de ágar e $800 \mathrm{ml}$ de água destilada). As placas foram incubadas nas temperaturas de 16, 20, 24, 28, 32 e 36 ${ }^{\circ} \mathrm{C}$, em escuro contínuo. Diariamente, até o sétimo dia, determinou-se o tamanho das colônias. Utilizaram-se três placas para cada temperatura e cada isolado.

Para se avaliar a formação de esporângios os dois isolados do fungo foram cultivados em meio CA por sete dias, sob luz contínua e temperatura ambiente. Após esse período, discos de meio de cultura contendo a massa micelial esporulante foram retirados com furador e tocados em gotas de lactofenol, em lâminas de vidro, a fim de se coletar assim os esporângios do fungo. Determinaram-se as medidas de 50 esporângios de cada um dos isolados: comprimento e largura dos esporângios; comprimento do pedicelo; largura e espessura da papila.

Para a formação de oósporos, um disco de $5 \mathrm{~mm}$ de diâmetro de BDA contendo micélio do isolado do fungo em 


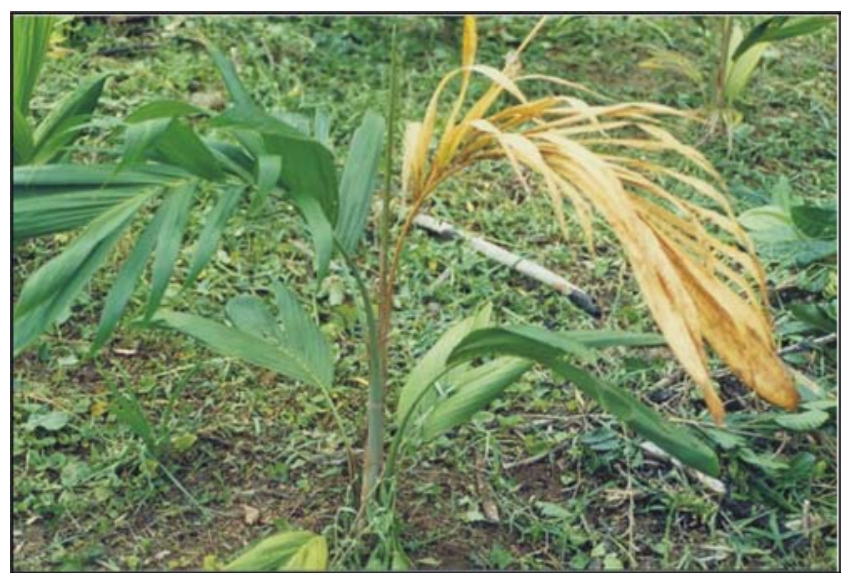

FIG. 1 - Planta de pupunha (Bactris gasipaes) com sintoma marcador - amarelecimento da folha bandeira causada por Phytophthora palmivora.

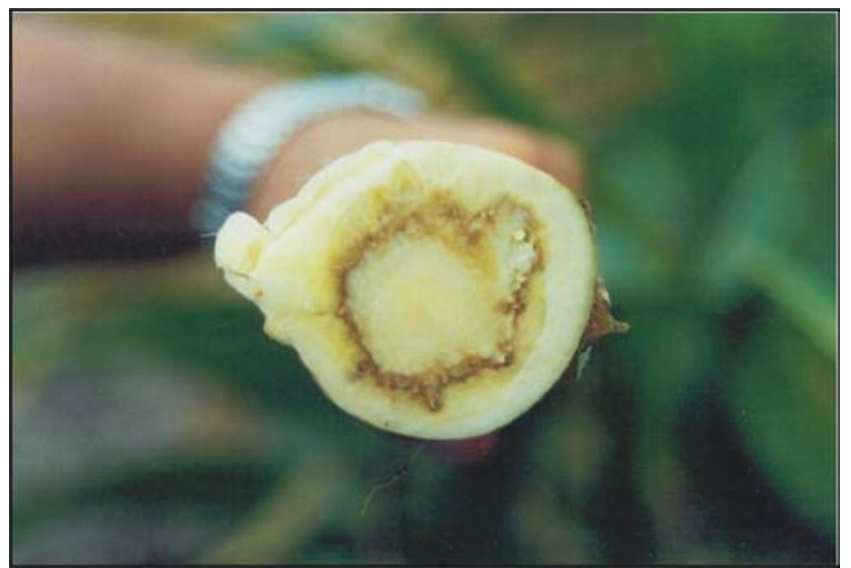

FIG. 2 - Corte transversal na base do estipe de planta de pupunha (Bactris gasipaes) com escurecimento dos tecidos internos.

estudo foi pareado em meio CA, com isolados padrões pertencentes aos grupos de compatibilidade A1 e A2 de Phytophthora capsici Leonian, distanciados a $3 \mathrm{~cm}$ um do outro. As placas foram incubadas no escuro contínuo, em temperatura ambiente, por quatro dias. Após esse período, avaliou-se a formação de oósporos na região de contato entre o micélio das duas culturas. A testemunha constituiu-se de dois discos do mesmo isolado em cada placa.

A ontogenia dos esporângios foi observada nos dois isolados pelo seu cultivo em meio CA, em escuro contínuo, por quatro dias, em temperatura ambiente. Após esse período, dez discos de $7 \mathrm{~mm}$ de diâmetro foram retirados e colocados em placas de Petri contendo uma lâmina de água destilada esterilizada, insuficiente para cobrir os discos. As placas foram incubadas sob luz contínua, em temperatura ambiente. Após dois dias de incubação foi observada ao microscópio a ontogenia dos esporângios.

O teste de patogenicidade foi realizado pela inoculação de mudas de pupunha, de um ano de idade, com discos de cultura de $7 \mathrm{~mm}$ de diâmetro produzidos em meio de BDA e depositados em furos circulares de $7 \mathrm{~mm}$ de diâmetro feito na base do estipe das mudas, a $5 \mathrm{~cm}$ do nível do solo. Após a deposição do inóculo envolveu-se o local da inoculação com fita adesiva e deixaram-se as plantas em casa de vegetação. A presença ou não de sintomas foi avaliada um mês após a inoculação. Foram inoculadas dez mudas para cada isolado e igual número de mudas sofreu o mesmo tratamento, mas não recebeu inóculo, servindo de testemunha. .

As culturas dos dois isolados, em meio CA e V-8, foram petalóides, com bordas difusas, micélio denso e cotonoso. Os isolados apresentaram o maior crescimento micelial entre 24 e $32{ }^{\circ} \mathrm{C}$ e nenhum crescimento a $35^{\circ} \mathrm{C}$. Os isolados BG-17 e BG-26 produziram no meio CA, $1,2 \times 10^{4}$ e $1,8 \times 10^{4}$ esporângios $/ \mathrm{ml}$, respectivamente. Os esporângios eram papilados, caducos, ovóides (Figura 3A) (relação comprimento/ largura de 1,5), formados simpodialmente, e pedicelos curtos. As dimensões médias de 50 esporângios dos dois isolados encontram-se na Tabela 1. Ambos isolados formaram regularmente clamidósporos em CA que apresentaram diâmetro médio de $3,8 \mu \mathrm{m}$ e espessura da parede de $0,2 \mu \mathrm{m}$ (Figura 3B). Os isolados mostraram-se heterotálicos, formando oósporos com anterídios anfígenos, pertencentes ao grupo de compatibilidade A2.

Os isolados foram patogênicos às plantas de pupunheira reproduzindo sintomas similares aos observados no campo. O reisolamento do patógeno das plantas doentes inoculadas foi facilmente obtido.

Pelas características culturais e morfológicas, os isolados do fungo patogênico à pupunha foram identificados como pertencentes à espécie Phytophthora palmivora (Butler)

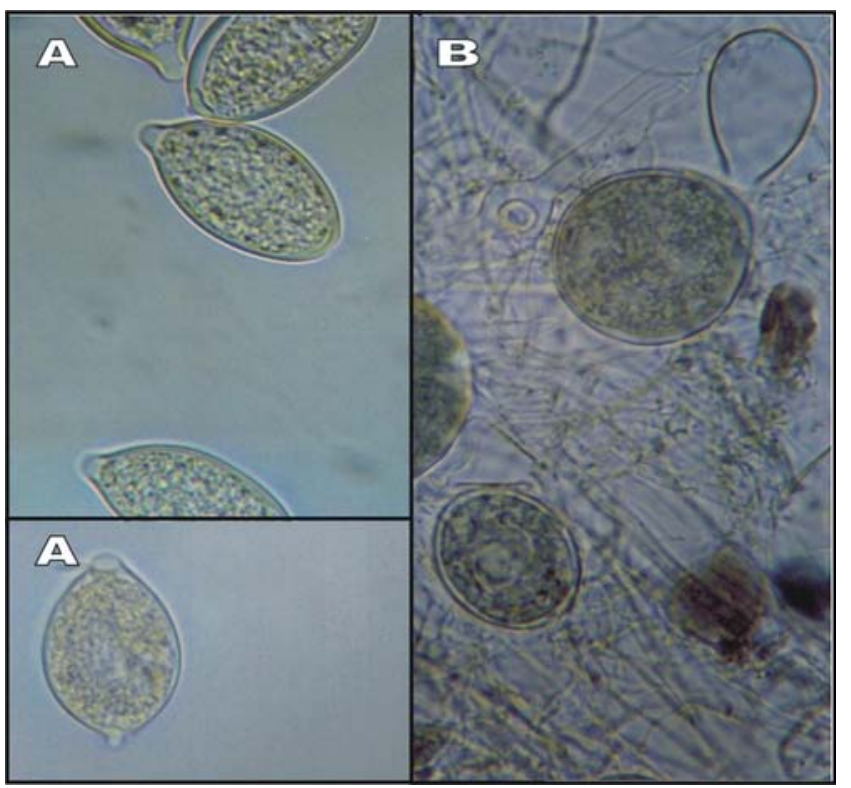

FIG. 3 - Esporângios (A); Clamidósporos (B) de Phytophthora palmivora. 
A.F. Santos et al.

TABELA 1 - Características e dimensões dos esporângios de dois isolados de Phytophthora palmivora obtidos da pupunheira (Bactris gasipaes) no Paraná

\begin{tabular}{|c|c|c|c|c|c|c|c|c|}
\hline \multirow{2}{*}{ Isolado } & \multicolumn{3}{|c|}{ Esporângios $(\mu \mathrm{m})$} & \multicolumn{2}{|c|}{ Papila $(\mu \mathrm{m})$} & \multirow{2}{*}{ Pedicelo } & \multirow{2}{*}{ Ontogenia } & \multirow{2}{*}{ Forma } \\
\hline & Comprimento (C) & Largura (L) & $\mathrm{C} / \mathrm{L}$ & Profundidade & Largura & & & \\
\hline BG-17 & $46,4 \pm 5,73^{\mathrm{a}}$ & $30,7 \pm 2,8$ & 1,5 & $7,9 \pm 1,5$ & $6,4 \pm 1,4$ & $3,8 \pm 0,8$ & Simpodial & Ovóide \\
\hline BG-26 & $46,1 \pm 4,4$ & $29 \pm 2,3$ & 1,5 & $7,4 \pm 0,9$ & $6,3 \pm 0,9$ & $4,1 \pm 1,0$ & Simpodial & Ovóide \\
\hline
\end{tabular}

*Média de 50 esporângios; ${ }^{a}$ Média \pm desvio-padrão.

Butler, conforme segue: esporângios caducos, papilados, ovóides; pedicelos curtos, ontogenia simpodial; clamidósporos esféricos, terminais ou intercalares; heterotálicos, formando anterídios anfígenos. Até o presente, no Brasil, a podridão do estipe da pupunha, causada por P. palmivora, foi relatada no Pará (Benchimol et al., 1998), em Pernambuco (Tavares et al., 1998) e em São Paulo (Pizzinatto et al., 2002). Este é o primeiro relato da ocorrência de $P$. palmivora associada à podridão do estipe da pupunheira no estado do Paraná.

\section{REFERÊNCIAS BIBLIOGRÁFICAS}

BENCHIMOL, R.L., ALBUQUERQUE, F.C. \& MULLER, C.H. Podridão da base do estipe da pupunheira causada por Phytophthora palmivora. Fitopatologia Brasileira 23:181. 1998.

NEWHOOK, F.J., WATERHOUSE, G.M. \& STAMPS, D.J. Tabular key to the species of Phytophthora de Bary. Kew, Commonweath Mycological Institute. Mycology Papers 143. 1978.

PIZZINATTO, M.A., BOVI, M.L.A., FEICHTENBERG, E. \&
SPIERING, S.H. Ocorrência da podridão do estipe em pupunheira, causada por Phytophthora palmivora, no estado de São Paulo. Summa Phytopathologica 28:363-365. 2002

RIBEIRO, O.K. A sourcebook of the genus Phytophthora. Lehre, Germany, J. Cramer. 1978.

SANTOS, A.F. DOS. Gomose de Phytophthora da acácia-negra. In: Luz, E.D.M.N., Santos, A.F. dos, Matsuoaka, K. \& Bezerra, J.L. (Eds.) Doenças causadas por Phytophthora no Brasil. Campinas, Livraria Rural. 2001. pp.67-90.

STAMPS, D.J., WATERHOUSE, G.M., NEWHOOK, F.J. \& HALL, G.S. Revised tabular key to the genus Phytophthora. Wallingford, CAB International Mycology Papers 162. 1990.

TAVARES, S.C.C. de H., NASCIMENTO, A.R., LIMA, J.A.S., MENEZES, W.A. \& CRUZ, S.C. Doenças da pupunha em áreas irrigadas na região do submédio São Francisco. Fitopatologia Brasileira 23:286. 1998. (Resumo).

WATERhouse, G.M. The genus Phytophthora de Bary. Diagnoses (or descriptions) and figures from the original papers Kew, Commonweath Mycological Institute. Mycology Papers 122. 1970 